\title{
Labor Pain through the Eyes of Brazilian Women and Delivery Nurses
}

\author{
Rafaela Feitosa Coutinho',2, Taiane da Silva Alves', Alecssandra de Fátima Silva Viduedo3, \\ Rejane Antonello Griboski'3, Casandra Genoveva Rosales Martins Ponce de Leon'3, \\ Juliana Machado Schardosim ${ }^{3}$
}

${ }^{1}$ School of Ceilândia, University of Brasília, Brasília, Brazil

${ }^{2}$ Maternity Hospital Brasília, Brasília, Brazil

${ }^{3}$ The Undergraduate Program in Nursing, School of Ceilândia, University of Brasília, Brasília, Brazil

Email: rafafcoutinho@gmail.com, taianealves_@hotmail.com, aleviduedo@hotmail.com, ra.griboski@gmail.com,

casandrapleon@gmail.com, julianamachado@unb.br

How to cite this paper: Coutinho, R.F., da Silva Alves, T., de Fátima Silva Viduedo, A., Griboski, R.A., de Leon, C.G.R.M.P. and Schardosim, J.M. (2018) Labor Pain through the Eyes of Brazilian Women and Delivery Nurses. Open Journal of Nursing, 8, 78-92. https://doi.org/10.4236/ojn.2018.81007

Received: December 6, 2017

Accepted: January 27, 2018

Published: January 30, 2018

Copyright ( 2018 by authors and Scientific Research Publishing Inc. This work is licensed under the Creative Commons Attribution International License (CC BY 4.0).

http://creativecommons.org/licenses/by/4.0/

\section{cc) (i) Open Access}

\begin{abstract}
Objective: Understanding the perception of women who have recently given birth in a Brazilian hospital regarding labor pain and nursing involvement in the labor process. Methodology: exploratory, descriptive and qualitative study carried out in a Maternity part of the supplementary health system in the Federal District (DF). Data were collected between May and July 2015 through interviews using a semi-structured questionnaire. The sample consisted of 16 mothers and data analysis followed Bardin methodology in three phases. Results: The pain experienced during labor is surrounded by feelings and expectations. Both positive and negative feelings experienced by mothers were identified in the interviews and unanimous opinion was the fact that the second stage is the most painful period as continuous pain is experienced. Some of the participants compared pain with strong menstrual cramps, renal colic and back pain; others, said labor pain was the strongest ever experienced. The immediate contact with the newborn was referred to as a reward for coping with breast pain and suffering. Other factors such as the importance of follow-up, support and coping with the pain and care provided by health staff were also highlighted. Conclusion: empowerment of the mother and family through knowledge is considered an important tool to fight pain and cope with the birth process in a positive and physiological way, which in the long run promotes a cultural change in the population regarding the importance of vaginal birth.
\end{abstract}

\section{Keywords}

Labor Pain, Supplementary Health, Birth Humanization, Obstetrical Nursing, Nursing Care 


\section{Introduction}

Didactically, labor is divided into four clinical stages: dilation, expulsion, placental and recovery. Birth pain involves subjective experience influenced by cultural, ethnic and social factors [1].

Physically, pain can be defined as a physiological expression mechanism of defense against a real "attack" or with similar attack potential [2]. It can be described and identified by different expressions and (verbal and non-verbal) reports of symptoms [3].

Throughout history there has been a cultural transformation about delivery preference and the pain related to vaginal birth was also a contributing factor in this process. Over the centuries the model of maternity care has changed, deliveries were home-based, assisted by midwives, and became predominantly hospital-based, assisted by doctors and nurses [4] [5].

The institutionalization of labor led to an assistance model in which the role was shifted from the mother to the professional that assists her and deliveries became instrumentalized (using forceps, episiotomy, lithotomy position, use of synthetic oxytocin, cesarean sections) [4] [5]. In this new model, due to the isolation of the pregnant woman, the use of instruments, submission to routines, among others, labor is now considered painful and pathological, and no longer a physiological act that all women can cope with [6].

Labor has always been, in the history of humanity, a process marked by pain experiences [7], but in past centuries such pain was considered culturally as a natural process having natural birth as main and first choice. Due to this cultural transformation an increase in c-section rates was observed worldwide, however, in Brazil this has been more evident. Studies add that the elective cesarean is more accessible to the population with higher purchase power-index close to $90 \%$ can be observed in the private health sector [8] [9]. Vaginal birth is surrounded by reports of painful experiences, and pain can influence couples to choose c-sections [8].

The pain experienced during labor can be classified as organic, acute, transient, complex, subjective and multidimensional [7]. Labor pain is caused initially by uterine contractions and then by the pressure exerted by the fetus in pelvic structures, during the expulsion period. Uterine contractions have intermittent characteristic, with gradual increase in intensity, duration and frequency until the end of the birth process [7].

Non-pharmacological methods for pain relief in childbirth assistance were introduced during the 90s in order to ease the pain during labor in a noninvasive manner and without the use of drugs. They are methods that do not require sophisticated equipment and can be performed by the person who is accompanying the parturient woman [10]. The most used methods are hydrotherapy, ambulation, change of position, acupuncture, acupressure, Swiss ball exercises, therapeutic touch, massage and breathing/relaxation techniques [11].

Combined with the use of non-pharmacological methods for pain relief, the 
presence of a person accompanying the parturient woman helps with their emotional control, which makes the sensation of pain to be less. It's also known that having a companion during the labor process provides many benefits, among which the main ones described in the literature are: strengthened affective and/or family ties, decreased anxiety of parturient woman, best evolution of labor and consequently physical and emotional comfort, which may allow for reduced levels of pain [12] [13].

In this scenario, nursing-as a professional category that monitors patients' progress $24 \mathrm{~h}$ a day-plays an important role in assisting labor. The constant presence of a nurse and a receptive attitude regarding the delivery plan brought by the parturient woman may represent an additional level of security and promote physiological progress in labor through trust in the team and institution. Considering the above, the objective was to understand the perception of postparturient woman in a Brazilian hospital regarding labor pain and nursing involvement in this process.

\section{Methodology}

Exploratory study with qualitative approach. Data collection was carried out at the maternity of a Brazilian hospital. The study population was comprised of postparturient woman under recovery from natural birth. The final sample included 16 participants.

Sample selection was made at random. Every day 6 women were drawn, being 3 for interview and 3 as replacements in case of refusal. The invitation for participation in the study was carried out in their room and acceptance was upon signing of Informed Consent Form (ICF). Inclusion Criterias: Women who had recently given birth (postparturient) over the age of 18 years and up to 24 hours of puerperium were included in the study. Exclusion Criterias: Women with mental disorders or cognitive deficits, victim of some kind of sexual, physical or moral harassment and those whose babies died, were excluded from the study. Women who received drugs to relieve labor pain and women who used synthetic oxytocin during labor were also excluded.

Analysis of patient's record and semi-structured interview, with open questions, carried out in a reserved location with each woman, were used for data collection (Frame 1). Interviews were recorded and transcribed for comprehensive use of their content. Data saturation criterion was used to stop data collection. Content analysis was based on Bardin (2011) [14] referential in three stages: pre-analysis, exploration of material and treatment of results/inference/interpretation.

The ethical principles were observed, following the provisions set forth in Resolution 466/12 of the National Health Council [15]. The research project was approved by the ethical committee of the hospital where data was collected. Interview recordings will be kept by the researcher for 5 years, and will be destroyed afterwards. In order to keep participants anonymous, their names were replaced with names of gemstones in the transcription of the dialogs. 
Frame 1. Semi-structured interview with open questions.

Interview Open Questions

Did you have a choice in childbirth?

Was it explained to you in the prenatal care about the two routes, both vaginal and cesarean section?

Was the pain of labor as you expected?

When did you feel the most pain?

Can you compare this pain with some pain you have already felt?

Did the nurse try to ease your pain? In what way?

What did you feel in the moment of pain? What feelings?

Were you with a companion? Could you choose the companion?

- If so, did your presence cooperate?

- If not, how do you think it could have been?

At the time of the strongest pains during labor, what was going through your head?

Can you report how you felt before and after birth, now what?

- Would you like something different?

\section{Results and Discussion}

The study's final sample included 16 postparturient women. Participants were between 19 and 34 years old, with average of 28 years. Most women were married and completed higher education. Household average was five minimum wages (minimum wage $\mathrm{R} \$ 788.00$ ), almost all had paid work, and the majority were civil servants (Table 1).

As for the obstetric history, there was a predominance of primigravidas with an average gestational age of 38 weeks. All of 6 multiparous interviewed had vaginal births in previous pregnancies. Regarding the choice of vaginal birth, it's relevant to say that women reported free and conscious decision. All of them had the presence of a companion of their choice at the time of delivery and some even chose to hire a doula and/or obstetrics nurse to accompany their labor (Table 1).

From the analysis of content, the data was grouped in three categories of analysis, as follows:

\section{Category 1: Characterization of labor pain}

This category grouped data related to the pain characteristics, expectation of the pregnant woman, feelings experienced in relation to pain during labor and comparison of labor and delivery pain with other forms of pain previously experienced.

The reports obtained in the interviews showed that labor pain can be related to the sense of despair and a desire that the process was sped up, or to be over as soon as possible, as mentioned by the participants. A report of surprise from participants for having overcome the expectation of coping with the pain, although such pain being stronger than expected at times, and a report of fear of pain. The sections below provide this information:

Then I felt like giving up half way through, because it gets to a point where even though you are expecting pain, it is stronger than expected (Amazonite). 
Table 1. Sociodemographic and Clinical Characteristics.

\begin{tabular}{cc}
\hline Sociodemographic Characteristics & N (\%) \\
Age* & 28 years \\
Marital Status & $13(81.25)$ \\
Married & $3(18.75)$ \\
Widow/Single & 13.37 years of study \\
Education $^{*}$ & 5 minimum wage \\
Household & \\
Gainful Activity & $16(100.00)$ \\
Yes & $0(0.00)$ \\
No & \\
Clinical Characteristics & $10(62.50)$ \\
Parity: & $6(37.50)$ \\
Primigravidas & 38 weeks \\
Multiparous & \\
Gestational Age & \\
\hline
\end{tabular}

${ }^{*}$ Data expressed in average.

[...] So, I didn't have that magical thing, but when contractions stopped, I could relax. But I was struggling, wanting it to be over, but at the same time, when the baby is born, then we really get into another mood. But up until that stage, you start to get desperate, like "' 'mon, let's get this thing over" (Beryl).

I think it was more of a surprise, because the pain was very strong. I didn't expect it to feel such strong pain, [...] surprised for having managed it and not having felt sick, because in the delivery room I wasn't on saline solution, or anesthesia or anything. So it was the surprise of feeling such pain, of having managed and having done it very fast (Quartz).

Historically, labor pain is related to something unbearable and physically painful. Over the centuries, a culture of pain related to labor was built as an idea of suffering, perpetuating the idea of childbirth as a traumatic moment for women from a physical and emotional point of view [7]. Therefore, from the last report above it's possible to observe that pain is intermittent allowing the parturient woman to rest between contractions.

Other matter related to coping with labor pain, observed in the interviews, was the felling of reward right in the first contact of the mother with the newborn, reported by them as a unique moment in which they understand the plenitude of life and the result of all effort necessary during labor. The immediate puerperium was described as a period in which emotions are running high. The first report presented below shows the importance of empowerment and respect for women's right to choose on their delivery route.

It's to do with love, plenitude, knowing that I was able to choose, right? I feel like crying (emotional). That I was able to choose, and that my baby arrived when he wanted, which is what I wanted! (Amazonite).

Wow, great! So rewarding! Him with us, we could touch, hug, and much more. It's great! (Amethyst). 
The next report shows the importance of immediate contact between mother and baby and the impact this has in order for the mother to forget all the pain and suffering experienced during labor.

Wow, after giving birth, when you see the baby coming out and crying, him recognizing you... because he did look at me. As soon as he came out, his eyes were already open and he held and squeezed my finger straight away. So I could have contact with him, which is something I wasn't expecting because I had read about it and thought the team would take him away from me immediately to clean and other things, but that didn't happen; as soon as he came out they put him on my arms. Hearing him crying, seeing that everything was ok, and that he was healthy, was the best thing ever (Onyx).

Sensation after birth is described as a moment of reduced anxiety when pain is ignored. Thus, feelings of labor fear, tension and pain are replaced by different sensations upon seeing the baby. During this period, it's common for the mother to report a sense of comfort, joy and gratitude, tied to the feeling of "victory" by the end of delivery with mother and baby, both healthy. The first contact between the mother and the newborn as well as the early start of breastfeeding provide psychic benefits for the life of every child, favoring the bond between the baby and their family [16].

Pain is a personal factor, however, the participants showed similar characteristics concerning its intensity. The interview transcriptions show that pregnant women's expectations often do not match their impressions regarding the intensity of the pain experienced. The pain expected can be more or less than the actual pain experienced during labor and childbirth.

It was worse (laughs), I knew it was going to hurt, but my God, it hurt twice as much (laughs). I thought of giving up, near the end (Amethyst).

It was much less. I must say. contractions hurt the most. When contraction would start, as dilation wasn't sufficient yet, I couldn't push, and it wouldn't go away-the pain was really strong. The moment I lay down on the birthing bed, it was a matter of minutes, I pushed about three times and he was born (Onyx).

The changes imposed on the mother's body during pregnancy, consist of physical and emotional preparation for childbirth [3] [11]. These changes, linked to culture, will influence the intensity of pain during and while going through the birth process, which will impact positively or negatively the impression and evaluation of the pregnant woman on the delivery routes, largely thinking on the culture regarding each delivery route [16].

Other important matter in the control of emotions during childbirth concerns adrenaline levels. At moments of pain, this hormone rates rise in the body, consequently the activity of the sympathetic nervous system increases, thus, increasing the hormones responsible for stress (corticotrophin-releasing hormone and adrenocorticotropic hormone), that act in defense of the body of the parturient woman. When the parturient woman keeps emotional control this defense mechanism decreases its activity and the production of oxytocin remains active for labor, which may become faster [10]. 
The participants were asked to compare labor pain to other pain previously experienced. For some, such comparison wasn't possible, while other participants compared it with more intense menstrual cramps, kidney colic and back pain.

I can't say anything as I have never broken any bones (laughs). However, what I felt was very strong cramps. I ve always felt cramps, but this was fairly strong (Agate).

No, it was the strongest pain I ever experienced (incomparable) (Amber).

Yes, I can compare it with kidney colic, and depending on the intensity, kidney stone... It gets to a point where they feel the same (Citrine).

As $I$ ve had back pain and strong cramps, that's what I can compare with but a thousand times worse (Quartz).

In relation to the moment of more intense pain, it was possible to note that pain apex usually occurs in the expulsion stage. According to interviewees, in this labor phase pain tends to be continuous, with no pause for relaxation. The study then showed that pain during labor is different from pain during expulsion stage because it is intermittent, which allows breaks for relaxation of the parturient woman as well as physical and emotional preparation to cope with the pain of the next contraction.

[...] The pain apex was really that, expulsion stage, when there's nothing you can do, your own body makes the effort to push, so there's no way you cannot push (Ametrine).

Oh, I think that the worst is when you are reaching the end of contractions, to achieve 10-cm dilation, right? Then I think pain is much stronger, more unbearable, let's say that the other (labor pain) seem that will give you longer breaks and you can bear with, but the other (expulsion pain) is one after another and you can't even control it, plus you have to prepare for such pain, right? (Fluorite).

Labor pain has physical causes such as cervical stretching, intrauterine hypoxia caused by decreased perfusion during contractions, pressure on the urethra, bladder and rectum, and also stretching of pelvic floor muscles [11]. These characteristics are involved mainly in two stages: dilation and expulsion period, where dilation phase promotes visceral pain with painful stimulus characterized by the straining of the lower uterine segment and cervical dilation, and expulsion period promotes a somatic pain by straining and traction of the structures around the vaginal dome and pelvic floor and perineum leading to continuous pain [3].

Reports of parturient women and the literature consulted show that the pain experienced during labor not always corresponds to that expected by the woman (which may be more or less than the pain they imagined during pregnancy), in addition to being perceived as progressive along the process with pain apex occurring in the expulsion period. Pain has its specificities and influences related to the form of acting and thinking of a person, that is, related to culture, therefore each social group will perceive and bear with labor pain in their own man- 
ner [2].

Category 2: The importance of a companion while coping with labor pain

This category approaches the importance of the presence of a companion during labor and childbirth periods, based on the reports from interviewees. Despite this not being the main focus of study, its importance was clear for the control of the parturient woman and coping with pain and the labor process.

During the interviews, their opinion regarding importance of the presence of a companion in the birthing room was unanimous. From the participants' perspective, this factor made a difference and the main companion chosen by them was their husband/baby's father. Some participants highlighted the importance of emotional support provided by their companions to cope with childbirth, as follows:

[...] His presence collaborated a lot, because if I were on my own, Id have given up, gee! [...] It's a lot of pressure. That's a lot of mixed emotions, and if he hadn't asked me to hang in there, or said that I could do it, Id have given up (Amethyst).

His support was essential-helping me in breathing exercises, helping me in everything, even when calling the health care professional. And specially being there. I even told him that I was so surprised, because it was all very smooth in comparison to the first one, when he did not accompany me because it was through SUS and companions are not allowed (Coral).

It's highlighted that often the role of the companion, expected by the parturient woman, is only their companion and have somebody around to call the HCP, when needed. Thus, it's noticeable that it's not possible to define a profile for the person to be a companion of the parturient woman, as such profile will depend on what each woman expects from this person and this is why it's important for her to choose who her companion will be as per Law No. $11.108 / 2005$, and also considering that she knows who is the best person in her social circle to meet her expectations during labor [17].

Considering Coral's report, the lack of knowledge regarding Law No. $11.108 / 2005$ is noticeable seeing that such law guarantees the presence of a companion during labor, delivery and immediate postpartum [17]. As Law, it is valid in any health establishment and not only in private establishments as reported by the study participant. The lack of knowledge of the population interferes with the matter of autonomy of the mother and her family in the labor process. Many times, information is not presented, thereby ignoring the respect for the rights of citizens [18].

The following reports also show the indifference of professionals towards the pain experienced by the parturient woman and the importance of the companion in the sense of having someone by her side sharing her grief and feelings of fear and anxiety in relation to the "success" of childbirth. It's noticeable that the health team ends up incorporating the reactions of the parturient woman related to labor pain as something trivial/usual in their work environment which sometimes can be perceived as indifference towards the parturient woman. The pro- 
fessional should also commit to their work as a complete being (body, mind and soul) as this is a moment of tension and happiness to the family.

We feel safer, because it's a moment when you know that, no matter how many people you have around, you are the one suffering. So the good thing about having a person by your side is more a matter of knowing you re not alone, that you have somebody else with expectations, waiting, anxious and happy for that moment, this gives us more strength, because it's a very difficult moment. Going through this on our own wouldn't be nice (laughs) (Fluorite).

[...] the strength he was giving me and when contraction would start I could hold on tight to his hand (laughs), [...]. So, him being there with me, and being able to see my childbirth, because this wasn't allowed before. [...] So, to me that was a very important experience. Also, if he wasn't there with me I think even my fear would have been greater (Onyx).

The presence of a companion is a source of strength to the parturient woman, which impacts her labor, making it smoother, with control of her feelings, and ultimately a childbirth with less interventions. The companion would be there to assist the parturient woman with whatever she needs, including comfort measures such as massages, support and offer encouragement in moments of emotional distress [16].

For some authors, the baby's father is considered the ideal companion. In addition to influencing labor progress, such companion is important in creating bond with the newborn. Accompanying childbirth would involve feelings regarding taking responsibility on paternity, valuing the father's role in relation to the family [19].

Category 3: Nursing actions in the assistance to pregnant women and their repercussions concerning facing labor pain

This category approaches the importance of the role of the nurse from prenatal up until delivery, from the analysis of interviews with the participants. The Ministry of Health of Brazil recommends prenatal assistance to be warming, develop educational and preventive actions, without the use of unnecessary interventions, with early detection of gestational risks and establish a connection between the location where prenatal is carried out with the birthing location [20]. Educational strategies are widely used with pregnant women, however, in private healthcare services interested couples seek this means to obtain knowledge, since there's no offer as accessible as that provided by the Brazilian Unified Health System (SUS). Educational activities should not replace the dialogue in consultations, but serve to reinforce what has already been spoken individually in a doctor's appointment.

Through individual assistance orientations can be adjusted to the family's reality, observing their individual needs and peculiarities. Orientations favor security when facing labor, including when coping with labor pain. Throughout the prenatal monitoring the good relationship between the nurse and the pregnant couple promotes confidence in the professional for childbirth assistance [16].

The participants' reports show that while some reported receiving sufficient 
information regarding the labor process, other participants reported the need of an autonomous search by electronic means in order to obtain more information, as they felt the orientations provided during the appointments were not sufficient.

[...] I found it a little weak. If it wasn't for my own knowledge, I wouldn't know (Amethyst).

Yes, there was all the assistance process, and three general meetings. one on breastfeeding, other on natural delivery and another on routes and their benefits (Onyx).

Among the multiparous participants there were reports in which previous vaginal birth had been a positive experience which motivated them to choose this route again, and contrary reports, as follows:

Indeed, however, I already knew it because of my first childbirth that was natural [...] I already knew how it was, so I didn't ask for a lot of explanation. But I wanted it again (Citrine).

Sufficiently, my first was natural birth, and I didn't want the second to be natural again (Crystal).

During prenatal follow-up, orientations expected to be provided are regarding anatomical changes, pain physiopathological mechanisms, suggestion of activities involving pelvic muscle preparation for labor, doubts regarding hospitalization, phases of the first period of labor. Prenatal care represents a preparatory moment to avoid emotional and physical problems, as well as birth-related trauma [20].

In Brazil, there are two very different situations: public health services and private sector services. Women who seek public health services normally are of inferior social class, they don't have the option to choose the professional and health institution they want, as services organize the demand by address proximity and the professional that assists the family during prenatal often does not carry out delivery. Those who seek private services often are of superior social class, have the option to choose the professional and already start prenatal care with the same professional who will carry out delivery. In rare exceptions, some couples choose to look for the hospital on the day of delivery and are assisted by the emergency obstetrician.

The fact of choosing the professional and knowing that the same professional will assist from start to finish of the gestational process is believed to contribute to the professional-patient relation and promote better interaction at the moment of delivery. The relation between the professional and the family is very important to ease the fear that might emerge in the first period of labor. Fear can lead to psychic tension, which will result in the perception that the pain increases due to straining of organs and tissues. Such relation makes the parturient woman react securely and with peace of mind, which is something that will probably increase the physiology of birth process [5].

Care models in North America and Europe are known to be similar to the 
care of public health services in Brazil, however, it's important to highlight the fact that Brazil is a developing country and, currently, faces serious economic crisis, which worsens the low quality of attention to the most vulnerable population. The participants interviewed in this study were assisted in a private institution and through their reports it's noticeable the importance of the relation built with the assisting team, as per transcriptions below:

I believe that this support (from the professionals) is very important. If you tell them you will give up, specially to non-humanized doctors, they give up, and don't encourage you to continue; unless the baby is ready and there's no turning back - if c-section protocol cannot be met, then it has to be natural (Amethyst).

I was trying to be strong, like "pain is psychological and I have to be strong", and the doctor would say: "look, there are so many centimeters before you go to the birthing table and deliver. But if you want a c-section, Pll do it now!" I felt that light pressure, so I was wondering whether or not to have it done, and whether I would regret it (Onyx).

Therefore, it's important to conduct labor in a humanized manner, with respect and individuality in order for this to be a positive experience, reflecting a cultural transformation about childbirth. In Brazil the role of nursing in childbirth assistance is still very restricted because doctors represent the dominant professional category, however in environments where childbirth itself is carried out by the doctor, the nursing team follows-up with the parturient woman throughout labor and the doctor only plays their role in the expulsion period for fetal extraction and placental expulsion.

It is known that the periodic sensitization of the professionals is very important to the maintenance of the humanization in the assistance, therefore, training courses and immersion skills are valuable for nurses to provide the assistance in the ideal way. Labor incentive issues are also motivating for workers of any category, including for nursing.

In Brazil, medical hegemony has caused many nurses to shift focus from their activities to bureaucratic issues or random procedures, leaving direct follow-up of labor to doctors, doulas, and nursing technicians. The movement for the humanization of childbirth and government incentives for specialization in obstetric nursing has favored the rescue of the nurse in the direct assistance to labor.

Another point to be highlighted is concerning elective cesarean-section. The previous report shows ease of access to this surgery by the population assisted in supplementary health services. The next report shows a false impression of greater risk control in c-sections, even though such data has not been confirmed by health care professionals yet.

She told me that it would be better if it were natural, because I would bleed less. This, in truth, is something that did not happen. Because in natural birth I lost a lot of blood. Really, a lot! And under c-section there could be certain control. There he told me that I would lose a lot of blood, etc... and what happened was that he scared me because of the problem of thrombocytopenia and I chose to have natural delivery (Agate). 
Study showed a higher frequency of postpartum hemorrhage, infection, embolism, placenta previa, placenta accreta, uterine rupture, hysterectomy periparto, besides presenting delayed in the beginning and shortest time of breastfeeding exclusive in the c-section in comparison to natural delivery [21]. It's also known that elective c-section increases 120 times the chance of breathing problems for the newborn and triples the risk of mother's death [9].

Many times, the information provided by the health care professional needs to be reinforced by lay people who went through the same experience so that the parturient woman considers it reliable and/or accurate, as shown below.

I already wanted from the beginning, but there was a discussion because I have vagovagal, and there was the risk of me passing out during delivery. Until the last days, and I had many doubts, but then I spoke with a person who also had the same problem and had natural of 41 weeks, and she had crisis during gestation. Then I got more excited about having natural delivery (Quartz).

The support of health care professionals during labor refers to assisting the parturient woman when experiencing pain and discomfort, giving them suggestions as to positions or situations in which she may feel better, providing security and making labor a pleasant moment for her, also by reducing the incidence of unnecessary interventions [5]. Nurses and doulas are seen as the key professionals to perform these actions.

In Brazil, the role of an obstetrics nurse is supported by Professional Practice Law No. 0447/2015 as responsible for performing the delivery without shoulder dystocia, perform an episiotomy, episiorrhaphy and application of local anesthesia, when necessary. Their importance is also highlighted as educator in health, aiming at the improvement of the quality of life of the population [22]. Doula is a skilled professional to provide emotional support and pain relief through non-pharmacological methods. The reports below corroborate the importance of a multidisciplinary health team in supporting labor and effectiveness of non-pharmacological methods for relief of the pain referred by the participants.

As I had a doula, I was in a room where I had a shower, Swiss ball and massage (Amethyst).

[...] because I was at home throughout labor, with a nurse, there I had the massage, they put me under the shower, and gave me the ball. [...] I came here with 4-cm dilation already, and the doctor here said "now you' re entering active labor". [...] my intention was to arrive here with $7-\mathrm{cm}$ dilation. But that didn't happen. [...] And then I was very disappointed and I told myself, I had opted for c-section, as I already had that on my head, but then things turned out differently (Kyanite).

It was, they would come and tell me to do the exercises, they asked me to walk; that's important right? Shower, hot water running on my back, that's quite a relief, and also helps with dilation! It was very important to do these types of exercises, they really helped. They even helped to speed up the process (Fluorite).

The incorporation of non-pharmacological methods for pain relief in hospitals began in the 90s. During this period, major advances in knowledge and prac- 
tices have been observed. The benefits of these methods relate to help in the descent of the fetal presentation, in perineal and body muscles relaxation, pain relief, as well as the promotion of comfort and decrease in emotional levels such as stress and anxiety [23].

Another important factor to be discussed is the pre-hospital monitoring performed by the obstetrics nurse at home as a way to delay the trip to the hospital, avoiding lengthy hospitalizations and physical weariness during labor, as reported above by Kyanite. The expansion of the movement for labor and birth humanization has promoted some changes in labor care in Brazil, and this type of assistance is becoming more frequent. In the last years, the number of women seeking planned home births and labor pre-hospital follow-up has increased among users of private health services; unfortunately, such assistance is still not accessible to poorer tiers of the population due to financial costs; however, for obstetrical nursing this is a work market in expansion.

\section{Final Considerations}

After the development of this research it was possible to understand aspects related to the pain experienced during labor. The subjective character of perception and coping with pain in labor and childbirth is highlighted, as well as the identification of expulsion period as the most painful period of the birth process, for this sample.

In the Supplementary Health System, it's noticeable that women have access to humanized childbirth and non-pharmacological care for pain relief, an aspect often precarious in Public Health Services. The participants stressed the importance of having a companion for emotional control and pain management, as well as the importance of the knowledge about the physiology of labor for a more secure attitude while in labor. Then, prenatal was highlighted as an important period in the emotional preparation of the pregnant couple and as an empowering tool for the pregnant woman so she can play the major role in the birth of her child.

It's also worth noting that a new care model might be emerging in the private sector with the monitoring of the initial phases of labor at home, avoiding early hospitalization of the parturient woman and unnecessary interventions, as reported by some participants of this study. Obstetrical nursing is highlighted as key element for this new care model, since there's increasing demand for prenatal and labor monitoring by the obstetrics nurse and their role in non-pharmacological management of pain during labor.

\section{References}

[1] Santana, L.S., Gallo, R.B.S., Ferreira, C.H.J., Quintana, S.M. and Marcolin, A.C. (2013) Pain Location during Early Active Labor Stage. Revista Dor, 14, 184-186. https://doi.org/10.1590/S1806-00132013000300006

[2] da R.P.R., Franco, S.C. and Baldin, N. (2011) A Dor e o Protagonismo da Mulher na Parturição. Revista Brasileira de Anestesiologia, 61, 376-388. 
[3] Nilsen, E., Sabatino, H., Lopes, M.H.B. and de, M. (2011) Dor e comportamento de mulheres durante o trabalho de parto e parto em diferentes posições. Revista da Escola de Enfermagem da USP, 45, 557-565. https://doi.org/10.1590/S0080-62342011000300002

[4] Menezes, P.F.A., Portella, S.D.C. and Bispo, T.C.F. (2012) A situação do parto domiciliar no Brasil. Revista Enfermagem Contemporânea, 1, 3-43. https://doi.org/10.17267/2317-3378rec.v1i1.38

[5] Velho, M.B., Oliveira, M.E., de Santos, E.K.A. (2010) Reflexões sobre a assistência de enfermagem prestada à parturiente. Revista Brasileira de Enfermagem, 63, 652-659. https://doi.org/10.1590/S0034-71672010000400023

[6] Amorim, L.S.L. (2010) Minhas experiências com o parto sem dor. 2a edição. Universitária, Recife.

[7] Almeida, N.A.M., Medeiros, M., Souza, M.R. (2012) Sentidos da dor do parto normal na perspectiva e vivência de um grupo de mulheres usuárias do sistema único de saúde. REME-Revista Mineira de Enfermagem, 16, 241-250.

[8] Domingues, R.M.S.M., Dias, M.A.B., Nakumura-Pereira, M., et al. (2014) Processo de decisão pelo tipo de parto no Brasil: da preferência inicial das mulheres à via de parto final. Cadernos de Saúde Pública, 30, S101-116. https://doi.org/10.1590/0102-311X00105113

[9] Brasil, Agência Nacional de Saúde Suplementar (2015) Estímulo ao parto normal: Organização da atenção ao pré-natal, parto e nascimento.

http://www.ans.gov.br/aans/noticias-ans/qualidade-da-saude/2923-entram-em-vigo $\underline{\text { r-novas-regras-sobre-parto-na-saude-suplementar }}$

[10] Gayeski, M.E. and Brüggemann, O.M. (2010) Métodos não farmacológicos para alívio da dor no trabalho de parto: uma revisão sistemática. Texto \& Contexto Enfermagem, 19, 774-782. https://doi.org/10.1590/S0104-07072010000400022

[11] Zugaib, M. (2012) Zugaib Obstetrícia. 2 Edition, Manole, Barueri:.

[12] Santos, G.S., de Souza, J.O., de Almeida, L.S. and Gusmão, M.H. (2012) A importância do enfermeiro no atendimento humanizado no pré-parto. Diálogos \& Ciência, 31, 224-228. https://doi.org/10.7447/dc.2012.025

[13] da Silva, R.M., de Barros, N.F., Jorge, H.M.F., de Melo, L.P.T. and Ferreira Jr., A.R. ( 2012) Evidências qualitativas sobre o acompanhamento por doulas no trabalho de parto e no parto. Ciência \& Saúde Coletiva, 17, 2783-2794.

[14] Bardin, L. (2011) Análise de conteúdo. Edições 70, São Paulo.

[15] Brasil (2013) Ministério da Saúde. Resolução no 466, de 12 de dezembro de 2012. nº 12, seção 1, Diário Oficial da União, Brasília, 59..

[16] Frigo, J., Ferreira, D.G., Ascari, R.A., Marin, S.M., Adamy, E.K. and Busnello, G. (2013) Assistência de enfermagem e a perspectiva da mulher no trabalho de parto e parto. Cogitare Enfermagem, 18, 761-766. https://doi.org/10.5380/ce.v18i4.34934

[17] Brasil (2005) Lei n. 11.108. Altera a Lei n. 8.080, de 19 de setembro de 1990, para garantir às parturientes o direito à presença de acompanhante durante o trabalho de parto, parto e pós-parto imediato, no âmbito do Sistema Único de Saúde-SUS. Diário Oficial da União, Brasília.

[18] de Carvalho, V.F., da Costa Kerber, N.P., de Azambuja, E.P., Bueno, F.F., da Silveira, R.S. and de Barros, A.M. (2014) Direitos das parturientes: conhecimento da adolescente e acompanhante. Saúde e Sociedade, 23, 572-581. https://doi.org/10.1590/S0104-12902014000200017

[19] de Melo, R.M., de Angelo, B.H.B., Pontes, C.M. and de Brito, R.S. (2015) 
Conhecimento de homens sobre o trabalho de parto e nascimento. Escola Anna Nery Revista de Enfermagem, 19, 454-459.

[20] Viellas, E.F., Domingues., R.M.S.M., Dias, M.A.B., et al. (2014) Assistência pré-natal no Brasil. Cadernos de Saúde Pública, 30, S85-S100.

[21] Oliveira, A.R. (2013) Fatores associados e indicações para a prática de cesariana: um estudo caso-controle. Revista Portuguesa de Medicina Geral e Familiar, 29, 151-159.

[22] Conselho Federal de Enfermagem (2015) Dispõe sobre a atuação de Enfermeiros na assistência às gestantes, parturientes e puérperas. Resolução n. 0447, 14 de abril de 2015. Conselho Federal de Enfermagem, Brasília.

[23] Souza, E.N.S., Aguiar, M.G.G. and Silva, B.S.M. (2015) Métodos não farmacológicos no alívio da dor: equipe de enfermagem na assistência a parturiente em trabalho de parto e parto. Enfermagem Revista, 18, 42-56. 